\title{
Facilitating Pupils' Questioning Skills in Open Inquiry Learning Through an Investigable Question Formulation Technique (IQFT)
}

\author{
Norsyazwani Muhamad Dah ${ }^{1,2 \star}$, Mohd Syafiq Aiman Mat Noor ${ }^{3}$
}

\author{
${ }^{1}$ Sekolah Menengah Agama Repah, MALAYSIA \\ ${ }^{2}$ Universiti Pendidikan Sultan Idris, MALAYSIA \\ ${ }^{3}$ University College London, UNITED KINGDOM \\ *Corresponding Author: g-52129188@moe-dl.edu.my
}

Citation: Muhamad Dah, N., \& Mat Noor, M. S. A. (2021). Facilitating Pupils' Questioning Skills in Open Inquiry Learning Through an Investigable Question Formulation Technique (IQFT). Journal of Mathematics and Science Teacher, 1(2), em0005. https://doi.org/10.29333/mathsciteacher/11283

ARTICLE INFO
Received: 1 Aug. 2021
Accepted: 9 Sep. 2021

\begin{abstract}
Open inquiry learning is a pupil-centred approach in which pupils generate investigable questions for the purpose of planning and implementing their own science investigation. However, generating investigable questions is not an easy task and requires a structured approach. Therefore, this study was conducted to improve the practice of a teacher-researcher in developing an Investigable Question Formulation Technique (IQFT) in a Malaysian school. This article attempts to answer the following research question: How can a teacher-researcher develop an Investigable Question Formulation Technique (IQFT) to facilitate pupils in generating investigable questions? IQFT, the intervention introduced in this study, contains eight main steps, which were carried out in two cycles. These steps involved the processes of (i) planning action, (ii) taking action, (iii) collecting and analysing data and (iv) reflecting. Unstructured observations, pictures and pupils' writing were among the data collected. Narrative analysis was conducted, to describe how the teacher-researcher applied IQFT as an approach to facilitate pupils developing investigable questions. Despite pupils being able to formulate investigable questions using IQFT, the teacher-researcher realised that pupils need to be continuously trained in this area. In addition, the teacherresearcher found that teachers need to adapt the educational approach according to the teaching context, to enhance the learning outcomes.
\end{abstract}

Keywords: investigable questions, problem-solving, inquiry-based learning, open inquiry, secondary school science

\section{INTRODUCTION}

This study focuses on a teacher-researcher's initiative to develop the Investigable Question Formulation Technique (IQFT) in a Malaysian school, to facilitate pupils to construct investigable questions in an open inquiry learning process. The term teacherresearcher was first introduced by Stenhouse (1975) to explain the role of the teacher as a researcher conducting research on his/her own practice. The teacher-researcher concept was adapted to the narrative approach of this study to enable the teacherresearcher to narrate her experiences of implementing action research in a science classroom (McNiff, 2007; Whitehead, 1989). The teacher-researcher, as the first author of this study, developed and implemented the IQFT intervention with 48 pupils aged 13 years old. The second author of this article was a critical friend during the period of the study. His role is discussed in the methodology section.

\section{ISSUES AND PROBLEMS}

Action research begins with a reconnaissance phase, which offers an evaluation of the previous professional practices of a teacher-researcher (McNiff, 2017). The teacher-researcher harnesses a reconnaissance phase in the initial stage of an action research project to explore concerns, or problems in a particular situation (Kemmis et al., 2014). Thus, this study emphasises the evaluation of the teacher-researcher's professional practice to identify issues and challenges in the context of her own teaching. The teacher-researcher who conducted this study is a science teacher who has been teaching Form 2 (14-year-old), Form 4 (16year-old) and Form 5 (17-year-old) pupils for the past nine years. The teacher-researcher graduated in Science Education (Chemistry) and holds a master's degree in Science (Chemistry). In summary, the teacher-researcher who conducted this study has a satisfactory background and vast experience in the field of science education. 
In her early career as a teacher, the teacher-researcher often used the method of 'chalk and talk' in science teaching because this method saved a lot of time and it was easy to obtain teaching aids. Although whiteboards are useful to explain science concepts to pupils during teaching and learning, notably through drawing diagrams (Venema et al., 2013), their use poses some difficulties. For instance, not all pupils can see everything that is written, especially pupils sitting at the back of the classroom. Most importantly, pupils cannot understand the concepts of abstract science. The use of whiteboards also restricts the active involvement of pupils and makes them passive during teaching and learning. In addition, the teacher-researcher often uses textbooks as a reference source. The teacher-researcher's previous teaching practice contradicts the findings of Laronde et al.'s (2012) study, which found that $62.04 \%$ of teachers think that pupils learn more through experiments, as compared to $19.71 \%$ in virtual labs and $18.25 \%$ in chalk and talk. Moreover, Laronde et al.'s (2012) study, which offered an evaluation of teachers' practice, found that they use three teaching methods, namely chalk and talk (the Bernoulli principle), virtual laboratory (web-based teaching) and experiments (hovercraft construction involving problem-solving). With that, the teacher-researcher realised the importance of diversifying science teaching methods to optimise her abilities.

The method of copying notes and generating mind maps also became increasingly important for the teacher-researcher in past teaching and learning, as a method of enabling the science syllabus to be completed according to the set planning calendar. In addition, the teacher-researcher is aware of the view that science teaching and learning should emphasise the presentation of facts through memorisation and drill methods. Sometimes, compulsory science experiments or practicals are only conducted with pupils if there are sufficient laboratory apparatus and materials, or YouTube ${ }^{\mathrm{TM}}$ video screenings are used as an alternative. Nevertheless, the teacher-researcher is aware the current reform of the Secondary School Standard Curriculum (KSSM). This includes Higher Order Thinking Skills (HOTS), which seeks to bring about content changes in public examinations. This change necessitates a paradigm shift among science teachers so that they are less focused on teaching solely for public examinations or for the purpose of predicting what topics might come up (MOE, 2013). Instead, pupils need to be trained to think critically, to apply their knowledge in different contexts, as discussed in the Malaysia Education Blueprint 2013-2025.

Since 2018, the teacher-researcher has been involved in the Inquiry-based Science Education (IBSE) programme organised by the National STEM Center, Ministry of Education Malaysia and thus was appointed as the Head Coach of the IBSE programme for Negeri Sembilan. The purpose of this programme is to expose Science, Technology, Engineering and Mathematics (STEM) teachers to the IBSE approach that needs to be practised in their classrooms. In addition, the programme also aims to develop strategies to improve critical thinking skills, train teachers to be effective coaches and provide experience to teachers in applying the IBSE approach. Throughout the teacher-researcher's involvement on the programme, she has learned about relevant strategies to improve science teaching and learning, especially through the science inquiry approach. Although the teacher-researcher found that inquiry approaches offered positive effects for pupils' mastery of science process skills, notably through conducting investigations (Othman \& Md Salleh, 2019), she realised that pupils in her school context were still weak when seeking to generate and answer inquiry-based questions.

Studies show that pupils are more inspired to ask questions related to problems about themselves, their families and observations of others (Chin \& Osborne, 2008). In tandem with this, pupils exposed to the inquiry approach are enabled to solve problems independently while the teacher acts as a facilitator. However, the teacher-researcher found in her experience that the open inquiry approach is very difficult to conduct in the classroom. Thus, investigation through open inquiry is not a common approach utilised by science teachers in Malaysia (Yin Peen \& Yusof Arshad, 2014). Typically, investigable questions or problem statements and procedures are provided by the teacher to enable pupils to conduct investigations. Pupils in Malaysia are also not accustomed to submitting their investigation questions on their own (Jais, 2014). Furthermore, in science textbooks most of the proposed investigations are of a confirmatory inquiry nature, most of which already have questions and investigative procedures. Thus, the involvement of pupils in projects of an open inquiry nature gives them the responsibility to determine the purpose and questions of the investigation, thus enabling them to learn about the role of a scientist (Zion \& Mendelovici, 2012).

Investigation is an experimental form of exploration in science teaching and learning that requires the direct participation of pupils to answer constructed investigable questions (Lock, 1990). Thus, an investigable question is a basic matter that needs to be explained well in the initial stage of the investigation. Pupils can be guided to conduct investigations through strategies such as: (i) pupils are given questions, procedures and investigation results in advance (known as validation inquiries), (ii) pupils are given questions and procedures but not investigation results in advance (known as a structured inquiry), (iii) pupils are given questions but need to plan procedures and are not given investigation results in advance (known as guided inquiry), (iv) pupils need to construct questions, plan procedures and are not given investigation results in advance (known as an open inquiry) (Bell et al., 2005; Newell \& Simon, 1972; Rezba et al., 1999; Watts, 1991). Thus, an appropriate method is needed to guide the pupils in posing a problem statement that they themselves will solve.

When conducting an investigation through open-ended inquiry, pupils need to construct investigable questions and then plan their own procedures in order to answer the constructed questions. Investigable procedures can be planned by pupils using a variety of methods. Before conducting an investigation specifically through open inquiry learning, investigable questions are required. Investigable questions can be prepared by teachers, through science textbooks/references or questions constructed by pupils. When pupils conduct an investigation using investigable questions constructed by themselves, they are more motivated to learn (Dillon, 1988). Investigable questions can be constructed by pupils through activities in science teaching and learning (Keys, 1988). Pupils have tremendous potential to construct investigable questions based on their own imagination (Shodell, 1995). Pupils' investigable questions can be identified through the results of group discussions of past experiences in science learning and their daily lives. These questions typically stem from curiosity about the world around them as well as from a deep interest in understanding the world (Scardamalia \& Bereiter, 1992). 


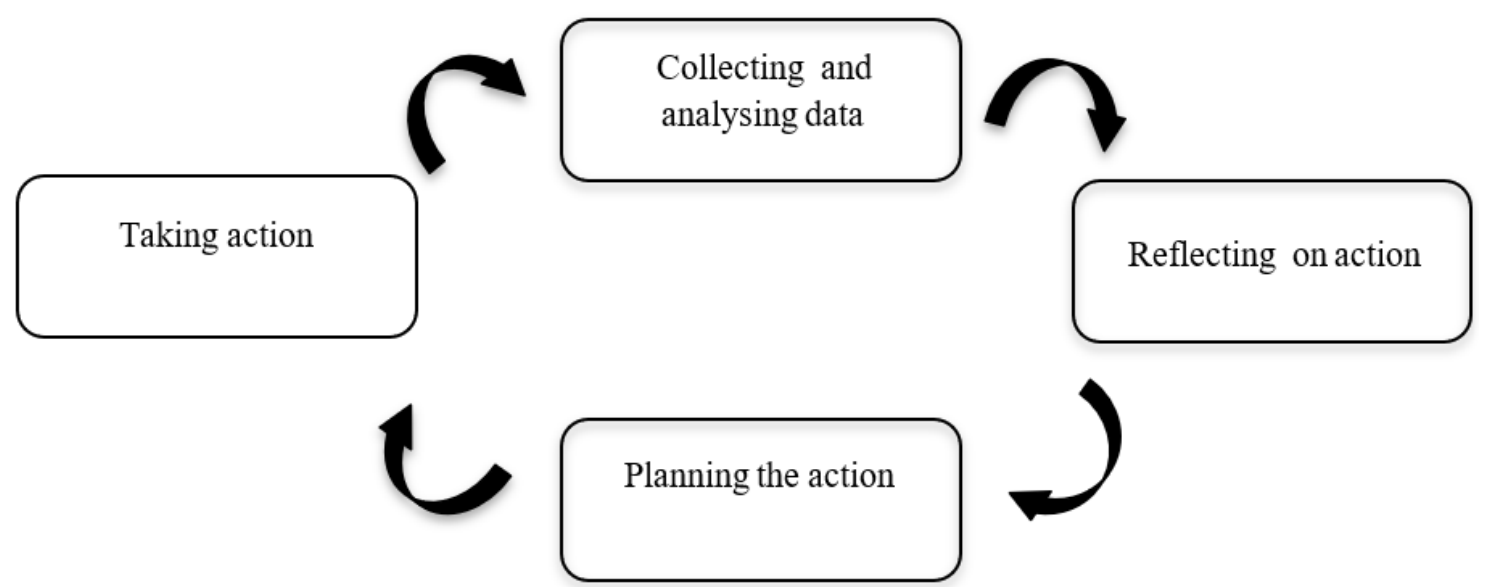

Figure 1. The research framework adapted from the action research model of Feldman et al. (2018, p. 9)

In previous science teaching and learning, the teacher-researcher always encouraged pupils to ask questions. However, as Sabu et al. (2018) explain, not many internal courses related to questioning techniques have been conducted for teachers in Malaysia. Pupils' questions are very important as a means of enabling the teacher-researcher to become aware of her readiness to accept the teaching content to be presented. This supports Chin and Osborne's (2008) statement that questions from pupils are a resource for teachers to find out the extent to which pupils seek to extend their knowledge. Typically, the teacher-researcher will ask pupils to read a relevant topic before they conduct an investigation. As a result of the reading, pupils need to construct some questions they want to ask before starting to learn. The questions constructed by the pupils are written into their ' $m y$ science notebook'. The 'my science notebook' is one of the resources used by the teacher-researcher to assess the development of pupils' learning in science subjects. However, the teacher-researcher's observations of the 'my science' notebooks found that most of the pupils were more likely to construct non-investigable questions, or, in other words, questions that were not scientific in nature. Thus, the biggest challenge that the teacher-researcher faced was to develop appropriate techniques because pupils were unable to ask questions in an investigable form.

The teacher-researcher also carried out an analysis of the questions constructed by the pupils in their 'my science' notebooks and found that the questions they recorded were sourced from the science textbook alone. During the science teaching and learning process, the teacher-researcher found that most pupils did not have questions to ask and that they themselves did not know the questions they wanted to ask. Such issues made the teacher-researcher upset and worried because pupils seemed to have an inability to construct investigable questions, which demonstrated a lack of critical thinking skills. Critical thinking is defined as the process of actively and skilfully disciplining intellectuals to conceptualise, apply, analyse, synthesise and evaluate information gathered from or produced through observation, experience, reflection, reasoning or communication, as a guide to belief and action (Scriven \& Paul, 2008). Critical thinking is a fundamental skill in science learning.

\section{FOCUS OF THE STUDY}

Inquiry learning is an important learning approach in science teaching and learning because it has great potential to foster critical thinking skills and promote self-learning among pupils (Chin, 2002). The teacher-researcher conducted this study to improve her practice by developing questioning techniques that allow pupils to construct investigable questions. Through investigable questions, open inquiry learning can be conducted in science teaching and learning. Accordingly, this article offers a qualitative and narrative analysis related to a central question: how can a teacher-researcher develop an Investigable Question Formulation Technique (IQFT) to facilitate pupils in generating investigable questions?

\section{METHODOLOGY}

This study uses the action research model of Feldman et al. (2018) which covers the process of action planning, taking action, collecting and analysing data, as well as reflecting on action, as shown in Figure 1. These four processes were carried out in two cycles for the duration of two months in an effort to improve the teacher-researcher's practice in developing an Investigable Question Formulation Technique (IQFT) in open inquiry learning. In cycle 1, the teacher-researcher introduced the technique of formulating questions adapted from Rothstein and Santana (2017) to both male and female Form 1 pupils. Through the first cycle, the teacher-researcher found that the questions constructed by the pupils were still less geared towards the form of investigation. Therefore, she improved the questioning techniques by introducing the Investigable Question Formulation Technique (IQFT). The teacher-researcher applied IQFT to the same group of pupils, namely Form 1 boys and girls in cycle 2 .

The IQFT intervention was developed as a result of a literature review of a combined research framework, encompassing the Question Formulation Technique (Rothstein \& Santana, 2017), SMART Goals (Brown et al., 2016) and Typology of Investigable and Non-investigable Questions (Chin, 2002). IQFT is a modification of the Question Formulation Technique (Rothstein \& Santana, 2017) which contains six components, namely: (i) question focus, (ii) question construct, (iii) open and closed questions, (iv) 
Table 1. The eight main steps of IQFT implementation

\begin{tabular}{|c|c|}
\hline Steps & Descriptions \\
\hline $\begin{array}{l}\text { Step 1: Identifying question } \\
\text { focus }\end{array}$ & $\begin{array}{l}\text { The teacher will identify the question focus as a stimulus for jumpstarting pupils' questions. This can be } \\
\text { achieved by using a short statement or a visual or aural aid in any medium or format that can stimulate pupil } \\
\text { thinking. }\end{array}$ \\
\hline $\begin{array}{l}\text { Step 2: Introducing question } \\
\text { rules }\end{array}$ & $\begin{array}{l}\text { The rules are: i) Ask as many questions as you can, ii) Do not stop to discuss, judge, or answer any questions, } \\
\text { iii) Write down every question exactly as it is stated, and iv) Change any statement into a question. }\end{array}$ \\
\hline $\begin{array}{l}\text { Step 3: Generating questions } \\
\text { individually }\end{array}$ & $\begin{array}{l}\text { Pupils will generate questions and the teacher will remind them to make sure to follow the rules and to } \\
\text { number each question they produce. }\end{array}$ \\
\hline $\begin{array}{l}\text { Step 4: Sharing and compiling } \\
\text { questions }\end{array}$ & $\begin{array}{l}\text { Pupils will be divided into groups of three to five pupils. Each group needs a pupil to serve as a leader to write } \\
\text { down the questions produced by all team members and manage other tasks. }\end{array}$ \\
\hline $\begin{array}{l}\text { Step 5: Introducing a SMART } \\
\text { rubric }\end{array}$ & $\begin{array}{l}\text { The teacher will introduce the SMART rubric to pupils, to enable them to identify investigable questions. } \\
\text { SMART refers to 'Specific', 'Measurable', 'Attainable', 'Relevant', and 'Timely'. }\end{array}$ \\
\hline $\begin{array}{l}\text { Step 6: Scoring investigable } \\
\text { questions }\end{array}$ & $\begin{array}{l}\text { The teacher will instruct pupils to review the list of formulated questions and to analyse these using the } \\
\text { rubric, to query whether or not the questions they produced fulfil any of the SMART characteristics. }\end{array}$ \\
\hline $\begin{array}{l}\text { Step 7: Prioritising investigable } \\
\text { questions }\end{array}$ & $\begin{array}{l}\text { Pupils will prioritise their investigable questions, to be shared with other groups based on the SMART } \\
\text { characteristics (i.e., the highest score). }\end{array}$ \\
\hline $\begin{array}{l}\text { Step 8: Reflecting on and } \\
\text { planning subsequent action }\end{array}$ & $\begin{array}{l}\text { The teacher will discuss the most prioritised investigable questions with pupils, to put forward a plan and to } \\
\text { begin a scientific investigation in an inquiry-based science education. }\end{array}$ \\
\hline
\end{tabular}

prioritising questions, (v) planning subsequent activities and (vi) reflection. A SMART Goal (Brown et al., 2016) is a goal or objective generated using SMART criteria, which is an acronym for 'Specific', 'Measurable', 'Achievable', 'Relevant' and 'Timely'. Meanwhile, the Typology of Investigable and Non-investigable Questions (Chin, 2002) categorises investigation questions as: (i) comparison, (ii) cause and effect, (iii) prediction, (iv) design and build, (v) exploration, (vi) explanation, (vii) pattern identification, (viii) problem solving, and (ix) prototype construction.

There are eight main steps in IQFT (as shown in Table 1), namely: (i) identifying question focus, (ii) introducing question rules, (iii) generating questions individually, (iv) sharing and compiling questions, (v) introducing a SMART rubric, (vi) scoring investigable questions, (vii) prioritising investigable questions, and (viii) reflecting on and planning subsequent action. While guiding pupils to construct investigative questions, they utilise various forms of thinking skills, notably being able to state observations made, provide justifications for cause and effect, construct hypotheses, state explanations, construct arguments and evaluate proposals submitted (Chin \& Osborne, 2010). In addition, questioning techniques allow pupils to think about a topic using Higher Order Thinking Skills, while giving them the responsibility for problem solving and understanding the content of the lesson (Jacques et al., 2020). Therefore, the development of IQFT in this study is the right choice in guiding pupils to construct investigable questions.

In this study the teacher-researcher involved 13-year-old Form 1 male and Form 1 female pupils in both cycles. The Form 1 male class consists of 25 pupils, while the Form 1 female class consists of 23 pupils. Most of the pupils achieved good scores (at least a C grade) for Science subjects in the last Primary School Achievement Test (UPSR). All pupils study in the Tahfiz stream, where pupils learn through the processes of reading, listening and reciting Quran. Pupils had gone through a rigorous screening process before being accepted into the teacher-researcher's school.

Although the findings of Salavera et al.'s (2019) study showed that the social skills of female pupils are higher than male pupils, in her past teaching and learning process, the teacher-researcher found that male pupils were more active and likely to come forward as compared to female pupils, who were more shy. Nonetheless, both groups of pupils had a deep interest in science. For example, the female pupils were inclined towards science-related digital drawing competitions while male pupils were interested in participating in competitions related to robotics and aerospace.

A critical friends group is an important element of action research, as it promotes collaborative practice (McNiff, 2017). The second author of this article was a critical friend and sought to enable the teacher-researcher to identify issues and problems, develop interventions and interpret research findings. In addition, the teacher-researcher was directly involved in a critical friends group with teachers of other subjects who jointly carried out their respective action research studies. The critical friends group consists of teachers from diverse educational backgrounds such as counselling, special education and mathematics. Meetings are held online on a regular basis to discuss and exchange views on their respective action research studies. Moreover, critical friends have been part of the support system that seeks to enhance the validity and credibility of the current study (Herr \& Anderson, 2005). Therefore, any elements of bias in the study have been reduced.

Data in this study were collected qualitatively using unstructured observations, photographic recordings and student work documents. Throughout the research process, the teacher-researcher conducted unstructured observations, i.e., direct observations that are also documented through photographic recordings. Although the collected data provided different interpretations, the teacher-researcher compared her interpretations with those of critical peers, as suggested by Feldman et al. (2018). Direct observation, especially during the implementation of the intervention, helped the teacher-researcher to collect very valuable data because such data can be drawn upon for teaching and learning, thus maximising the research impact. In addition, the teacher-researcher collected student work documents such as the 'my science notebook', science journals and flipcharts. All these data were analysed narratively and compiled (Feldman et al. 2018). This step sought to enable the teacher-researcher to explain how she had improved her practice as a Science teacher in the process of fostering open inquiry through IQFT. 


\section{FINDINGS}

During this study, the teacher-researcher made direct observations throughout the process of planning, taking action, collecting and analysing data, and reflecting. The following findings and discussion section will discuss these observations through narrative writing. In the process, it will seek to answer the research question, namely: how can a teacher-researcher develop an Investigable Question Formulation Technique (IQFT) to facilitate pupils in generating investigable questions?

\section{Cycle 1}

\section{Planning action}

Based on the issues and problems in science teaching and learning discussed in the introductory section of this article, the teacher-researcher began to develop appropriate questioning techniques by reviewing those developed by past scholars. The teacher-researcher used online search methods and as a result she found a video titled 'The Question Formulation Technique in a High School Science Class', uploaded by Right Question Institute, Massachusetts, USA (2016). The teacher-researcher continued reading in more detail about the Question Formulation Technique via the website https://rightquestion.org/what-is-the-qft/. She also noted that Rothstein and Santana (2017), two educators from Kyoto, Japan, have used the Question Formulation Technique. They reported that the technique can stimulate pupils' curiosity by encouraging them to ask questions. Thus, the findings of the study support the teacher-researcher's rationale to apply the Question Formulation Technique as an initial or experimental intervention in this study.

\section{Taking action, collecting and analysing data}

In the initial stage, the teacher-researcher applied the Question Formulation Technique (Rothstein \& Santana, 2017) to her work with Form 1 male pupils using a key science learning topic: the menstrual cycle. The teacher-researcher introduced the focus of the question to the pupils before they constructed the question. Question focus is a stimulus method to enable pupils to construct questions. The focus can be in the form of statements, phrases, pictures, videos, problems or mathematical equations. During this cycle, the teacher-researcher introduced the focus of the question to the pupils by providing a diagram of the menstrual cycle. The menstrual cycle diagram contained facts related to the menstrual cycle, notably that it typically lasts 28 to 35 days, and includes four phases, namely the menstrual phase, recovery phase, fertile phase and premenstrual phase. The teacher-researcher then introduced four rules of question construction, namely: (i) pupils need to construct as many questions as possible, (ii) pupils need to discuss these questions throughout the group activity, (iii) pupils need to evaluate the questions constructed, and (iv) pupils need to write each question clearly and convert any statements to questions.

Based on the menstrual cycle diagram, pupils were instructed to construct questions individually within the allotted time of between five to ten minutes. The teacher-researcher found that the stimulus material was useful i.e. the menstrual cycle diagram was fully used by the pupils in an effort to construct the question. The pupils were then instructed to share the questions they had constructed with their group members. The group leader combined the questions by writing them down on a piece of paper. Each group was also guided to identify the constructed questions as being of either a closed or an open type. Pupils wrote the symbol ' $C$ ' for closed questions and ' $O$ ' for open questions (as shown in Figure 2). They were also asked to convert closed questions to open questions and open questions to closed questions. Closed questions use question words such as what, when, who and how

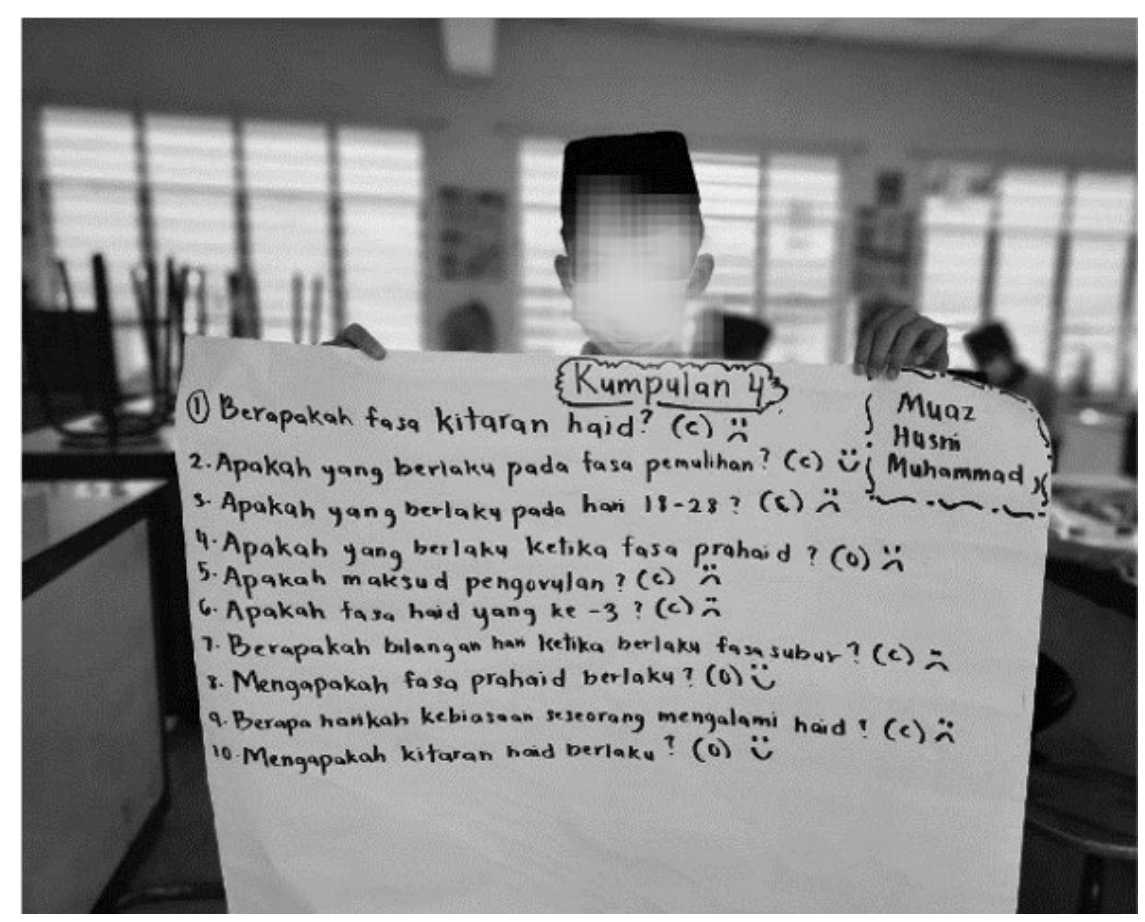

Figure 2. Questions generated by one of the groups of pupils 
Table 2. Questions constructed by male Form 1 pupils in Cycle 1

\begin{tabular}{cc}
\hline No. & Question Item \\
\hline 1. & "When does the menstrual cycle occur?" \\
\hline 2. & "Why can a wome of the factors that can affect the menstrual cycle?" \\
\hline 3. & "Why does the menstrual cycle occur and what are its effects?" \\
\hline 4. &
\end{tabular}

Table 3. Questions constructed by female Form 1 pupils in Cycle 1

\begin{tabular}{cc}
\hline No. & The questions \\
\hline 1. & "How long does the menstrual period typically last?" \\
\hline 2. & "Why is the $14^{\text {th }}$ day the day of ovulation?" \\
\hline 3. & "How can the menstrual cycle be modelled using a series of concrete materials?" \\
\hline 4. & "How long is each cycle of the menstrual phase?" \\
\hline 5. & "How does the ovulation process take place?" \\
\hline 6. & "Why do we have only four phases of menstruation?" \\
\hline 7. & "On what day does the fertile phase begin?"
\end{tabular}

much. Meanwhile, open-ended questions use question words such as why and how. As a result of the group discussions, pupils also identified investigable questions by drawing a smile emoji symbol, while non-investigable questions were denoted by drawing a sad emoji symbol.

Each group shared the questions they thought were investigable to the other groups. The questions constructed by the pupils and classified as investigable questions are shown in Table 2. Question 1 is a non-investigable question because the use of the question word 'when' yields limited answers. This question can only be answered with a factual answer that starts with the age of 9 to 16 years. Furthermore, question 1 was unclear, non-specific and pupils constructed the question according to their understanding and experience (as men). Question 2 is an investigable question because it can be categorised as exploratory. This question seeks to identify the factors that affect the menstrual cycle. Pupils can conduct an investigation by searching for reference materials such as textbooks, magazines and online materials to identify and explore the factors involved. Thus, this type of question is not focused, yet contains variables of interest. Question 3 and question 4 use the question word 'why'. Both of these questions are open-ended and non-investigable because they are unclear, non-specific and need complex information to yield answers.

Through the analysis of the questions constructed by the pupils, the teacher-researcher found that most of the questions generated by the male Form 1 pupils were non-investigable. Male pupils did not have any direct experience related to the focus of the question introduced, i.e., the menstrual cycle. Thus, the questions generated mostly led to limited answers and were based on their misunderstanding of a particular topic (or the focus of the question). This is also explained by Chin (2002) who states that the questions generated by pupils arise from their desire to add to their knowledge base and are not necessarily practical for an investigation to be conducted. Thus, Chin and Kayalvizhi (2002) are of the view that pupils need to be guided by teachers to convert non-investigable questions to investigable questions.

The teacher-researcher also applied the Question Formulation Technique (Rothstein \& Santana, 2017) to female Form 1 pupils, using the focus of menstrual cycle questions. The same technique was used for this group of pupils, namely: (i) introduce the focus of the question, (ii) introduce the rules to the pupils, (iii) pupils construct questions individually, (iv) pupils share questions constructed in groups, (v) each group identifies open or closed questions in the form of an investigation, and (vi) each group shares the selected questions with the other groups. When the teacher-researcher implemented this intervention with female Form 1 pupils, she found that they were quicker to construct questions after the question focus was introduced. Most of these Form 1 female pupils have self-experience related to the menstrual cycle process, which means that they have existing knowledge from their daily lives. The questions constructed by the pupils are shown in Table 3.

Similar to the findings from the male Form 1 pupils, the analysis of the questions constructed by female Form 1 pupils showed that only one question was investigable, namely question 3. This question can be categorised as one that seeks to validate a mental model. To answer question 3, pupils might work on designing and building up a concrete model that shows how the menstrual cycle really works. The other questions are non-investigable. Questions 1, 2, 4, 6 and 8 allow for limited answers. Questions 5 and 7 are unclear and non-specific. This coincides with Chin's (2002) work, as the questions generated by female Form 1 pupils are related to their interaction with real world problems and their desire to explore something relevant to their personal lives.

\section{Reflecting on the action}

The main insight that the teacher-researcher gained in Cycle 1 was an awareness of her own shortcomings in guiding pupils to construct investigable questions. The teacher-researcher found that the use of two-dimensional diagrams to work on the focus of the questions did not stimulate pupils to construct investigable questions. The classification of questions into closed and open also constrained the process of constructing investigable questions. Moreover, the teacher-researcher did not introduce the features of the investigable questions to the pupils. Pupils can also only produce questions according to their existing understanding and knowledge by using question words such as what, who, when, how much, why and how. In conclusion, the teacher-researcher was not satisfied with the findings of the intervention in Cycle 1 because the Question Formulation Technique 


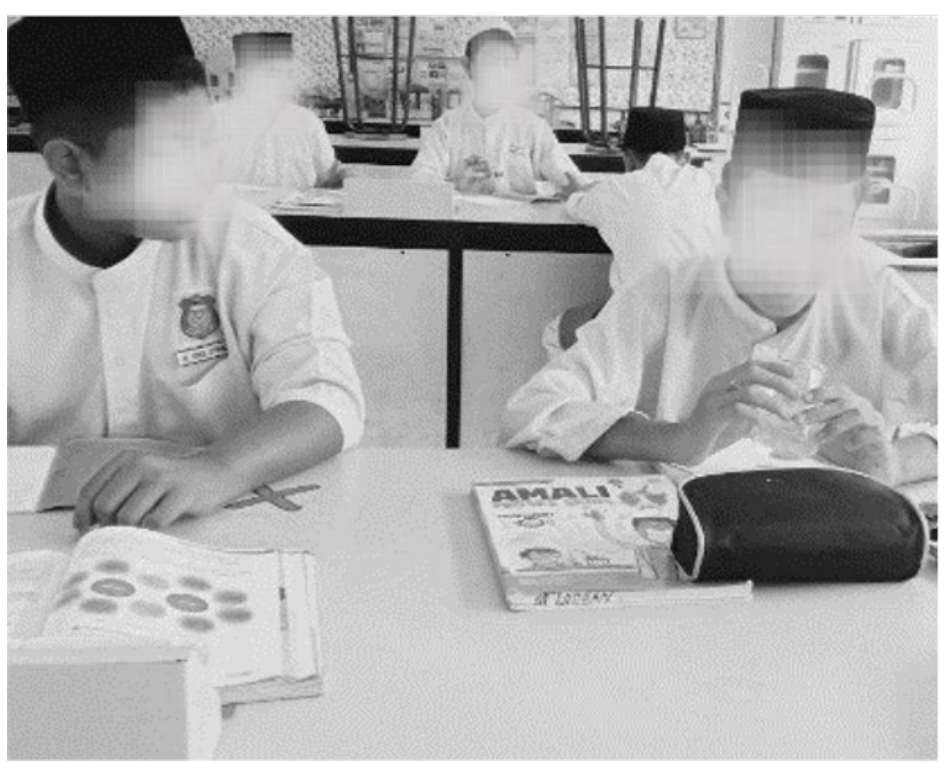

Figure 3. Pupils make observations on the ice used as the focus of the question

(Rothstein \& Santana, 2017) that the teacher-researcher introduced to pupils was less helpful to them constructing investigable questions than she had initially thought.

\section{Cycle 2}

\section{Planning the action}

Through the insights that the teacher-researcher gained from Cycle 1, she planned to modify the questioning techniques used in an effort to guide pupils to construct investigable questions in Cycle 2. The teacher-researcher initiated discussions with critical peer groups to improve the questioning techniques. As a result of the discussions and sharing through a group of critical peers, the teacher-researcher was able to develop the Investigable Questions Formulation Technique (IQFT). The difference between IQFT and the questioning techniques used in cycle 1 is that pupils construct questions individually, as applied in IBSE. In addition, pupils were introduced to the SMART rubric that they would use to identify which constructed questions were investigable or noninvestigable. The measures used to identify open-ended or closed-ended questions, as carried out during the intervention, in cycle 1 were not used in the IQFT questioning technique. IQFT has been explained in detail in the research methods section of this article.

\section{Taking action, collecting and analysing data}

At the beginning of cycle 2, the teacher-researcher applied the IQFT intervention to the male Form 1 pupils using the Science learning topic of matter. In step 1, the teacher-researcher introduced the focus of the question to the pupils by giving each group a beaker containing some ice cubes. Based on the initial observations, the teacher-researcher found that the pupils had applied a basic skill involved in the science process, namely 'observation'. Pupils made observations on the material using the senses of touch and sight (as shown in Figure 3). They were also observed touching the stimulus material and at the same time making observations on the ice melting process.

In step 2, pupils were reintroduced to the four rules of question construction. The teacher-researcher adapted four rules of question construction from the Question Formulation Technique (Rothstein \& Santana, 2017) in IQFT, namely: (i) pupils need to construct as many questions as possible, (ii) pupils need to discuss these throughout the group activity, (iii) pupils need to make an evaluation of the constructed questions, and (iv) pupils should write each question clearly and convert any statements to questions. In step 3, pupils are then guided to produce questions individually in the allotted time of between five to ten minutes. Through the observations that the teacher-researcher made, she found the stimulus material in step 1 to be useful, i.e., ice had stimulated the pupils to produce investigable questions. Each pupil had constructed more than one question related to the focus of the question, i.e., ice.

In step 4, pupils were instructed to share the questions they had constructed with their group members. The group leader was responsible for incorporating the questions generated by the group members by recording the questions on a piece of paper. In step 5, pupils were introduced to the SMART rubric as a guide for them to identify the investigable questions. SMART refers to specific, measurable, achievable, relevant and timely. Pupils needed to identify the constructed questions and whether they had met the SMART criteria, i.e., the constructed questions need to be specific, measurable, achievable (i.e., implemented successfully), realistic (i.e., allowing sufficient time to conduct the investigation). Based on the SMART rubric in step 6, each group had to assign a score to each question constructed by their respective group members (as shown in Table 4).

In step 7, each group listed the questions that yielded high scores and shared them with the other groups. Table 5 shows the high-scoring questions, as constructed by male Form 1 pupils. Of these, there are three investigable questions, namely questions 6, 7 and 8. Questions 4 and 6 can be categorised as exploratory questions, question 7 as a predictive question, and question 8 as a comparison question. Question 7 is a good example of an investigable question because pupils will make observations about the outcomes from their investigation. For example, pupils will engage in some trial and error, simple, hands-on activities to estimate 
Table 4. Score of questions using the SMART rubric

\begin{tabular}{ccccc}
\hline SMART & Question 1 & Question 2 & Question 3 & Question 4 \\
\hline Specific & $/$ & $/$ & $/$ & Question 5 \\
\hline Measurable & & $/$ & $/$ & $/$ \\
\hline Achievable & & & $/$ & \\
\hline Relevant & $/$ & $/$ & $/$ \\
\hline Timely & & & $/$ \\
\hline
\end{tabular}

Table 5. High-scoring questions were constructed by male Form 1 pupils during Cycle 2

\begin{tabular}{cc}
\hline No. & The questions \\
\hline 1. & "What will happen to the ice in the beaker after a few minutes?" \\
\hline 2. & "Why is the quantity of water increasing?" \\
\hline 3. & "What is the matter of ice after being placed at room temperature?" \\
\hline 4. & "Why does ice melt when receiving heat?" \\
\hline 5. & "Why does ice feel cold?" \\
\hline 6. & "What is the estimated mass of ice required to melt into 25 ml?" \\
\hline 7. & "Which condition will make ice melt quickly?" \\
\hline 8. & "Why does ice take so long to melt?" \\
\hline 10. & "What will happen to the ice if the temperature is high?"
\end{tabular}

Table 6. High-scoring questions were constructed by female Form 1 pupils in Cycle 2

\begin{tabular}{|c|c|}
\hline No. & The Questions \\
\hline 1. & "How can the ice in the beaker melt?" \\
\hline 2. & "What changes occur during the water cycle?" \\
\hline 3. & "What would have happened if the ice on the table had been put in the fridge?" \\
\hline 4. & "What can we observe from the ice cube?" \\
\hline 5. & "Which of these solutions will make the ice float in it?" \\
\hline 6. & "How long does it take for the ice to melt completely?" \\
\hline 7. & "What is the melting point of ice" \\
\hline 8. & "How can a solid turn into a liquid?" \\
\hline 9. & "What is meant by melting point?" \\
\hline
\end{tabular}

the mass of the ice. To answer question 6, pupils will seek to identify the factors that cause the ice to melt quickly. This means that the question that has been categorised as exploratory will not make pupils focus on particular variables. Meanwhile, question 8 is categorised as a comparison question because pupils need to compare a given characteristic within a set of specific conditions and make a selection. Questions 1, 2, 3 and 4 are non-investigable questions as they yield limited answers. Questions 5, 9 and 10 are also non-investigable questions as they are unclear and non-specific.

The IQFT intervention that used material topics and focused ice questions was also implemented with Form 1 female pupils. Table 6 shows the questions with high scores constructed by the pupils. Questions 2 and 5 are investigable questions. Question 2 can be categorised as a descriptive question, while question 5 is a comparison question. Descriptive questions require pupils to engage in some close observations, and to provide in-depth descriptions of objects. To answer question 2, pupils need to observe processes involving the water cycle in their everyday lives. Question 5 is categorised as a comparison question because pupils need to compare the properties of the solutions given and group them into categories based on their observations of what makes ice float. Questions 1, 3, 4, 6, 7, 8 and 9 are non-investigable questions as they offer limited answers and simple information. An example of a limited answer to question 7 is that the melting point of ice is $0^{\circ} \mathrm{C}$.

\section{Reflecting on the action}

In cycle 2 there was an increase in the number of investigable questions constructed by the pupils. The teacher-researcher found that investigable questions that could be categorised as predictive, exploratory, validation of mental model, comparison and descriptive (Chin, 2002) were more commonly constructed by pupils than other forms of investigable question. The use of material titles and the focus of ice questions also influenced the number of investigable questions constructed by pupils. This may be due to pupils' existing knowledge of the topic of matter and their daily experiences of ice, since pupils were introduced to questioning techniques in cycle 1. Thus, the process of implementing IQFT in cycle 2 went smoothly because pupils already had experience of using some of the questioning techniques. The teacher-researcher also found that the approach of teaching about question focus through existing materials, drawing on pupils' experience of using these materials, greatly helped them to construct investigable questions (Nik Yusuf et al., 2017). Thus, the teacher-researcher found that the selection of an appropriate topic is very important so that pupils can construct investigable questions through IQFT. 


\section{DISCUSSION}

The teacher-researcher has gained four main insights as a result of her involvement in this study. First, she has realised that the process of constructing investigable questions is complex, especially when undertaken as part of open inquiry learning. Yoon et al. (2012) explains that in science teaching and learning, teachers do not often practise three important elements, namely: (i) developing pupils' ideas and curiosity, (ii) guiding pupils to plan investigations to confirm hypotheses, and (iii) strengthening pupils' interpretations and discussion of findings. Furthermore, inquiry is a difficult learning approach because teachers confuse guided inquiry with open inquiry, lack an understanding of hypotheses and lack confidence in their science content knowledge (Yoon et al., 2012). The teacher-researcher also realised that her lack of skills in guiding pupils to construct investigable questions was leading to less effective inquiry learning. Thus, through the action research process, which includes the phase of planning action, taking action, collecting and analysing data, as well as reflecting on action, the teacher-researcher was enabled to develop the Investigable Question Formulation Technique (IQFT). In this study, the teacher-researcher showed that investigable questions can be nurtured among pupils. This is an important step, as previous studies have explained that investigable questions are not common in the teaching of science in Malaysia, let alone science teaching and learning using an open inquiry approach.

Second, the teacher-researcher found that a new technique introduced to pupils needs to be consistently applied, through a process of continuous repetition. Previously, pupils were not familiar with investigable questions and techniques for constructing investigable questions. Therefore, the process of repetition is very important in order to guide pupils to familiarise themselves with new techniques introduced in science teaching and learning. However, time constraints are the biggest obstacle to applying questioning techniques on a regular basis because the techniques take longer to develop than traditional teaching approaches. Fitzgerald et al. (2019) explain that teachers do not have much time to implement an inquiry-based investigative approach due to the extensive syllabus to be taught to pupils. In addition, the process of constructing investigable questions involves high-level thinking and critical thinking skills. This study provided a lesson for the teacher-researcher, namely to have patience when guiding pupils. This can be achieved by setting long-term goals, as the skill of constructing investigable questions cannot be achieved in a short time period. However, if pupils are familiar with the IQFT questioning technique, they will become more adept at constructing investigable questions.

Third, one of the teacher-researcher's key observations in this study was that the skill of constructing investigable questions cannot be taught to pupils directly. However, such skills can be applied in science teaching and learning using various topics found in the syllabus. The IQFT intervention developed in this study is universal in nature; it can not only be applied in pure Science subjects but also in other Science subjects such as additional mathematics, applied science, technology and vocational learning. In addition, the skill of constructing investigable questions is not only important to enable pupils to plan and conduct investigations, but also to be able to cultivate critical thinking skills. Pupils are unable to conduct an investigation if they are unable to construct an investigable question or if a constructed question is not investigable in nature (Harrak et al., 2019). Thus, the skill of constructing investigable questions also offers the opportunity to cultivate critical thinking skills, which are important for developing high-level skills to be applied to scenarios in daily life.

Finally, through her involvement in the study, the teacher-researcher found that an educational theory or pedagogy only serves as the knowledge base for teachers. However, teachers need to themselves decide how this should be applied. Teachers have a great responsibility to adapt an educational theory or pedagogy according to the local context of the school, teachers and pupils. In the early stages, the teacher-researcher adapted the Question Formulation Technique from the study of Rothstein and Santana (2017) in Cycle 1; however, she also found that some elements in the technique needed to be modified. Thus, in Cycle 2 she developed an IQFT intervention that incorporated the research framework of Chin (2002), Brown (2016) as well as Rothstein and Santana (2017), adapted to the context of her own teaching. Thus, modifying an educational theory or pedagogy is very important because teachers need to have a deep understanding of their local teaching context.

\section{CONCLUSION}

Generating investigable questions is not a simple task as it requires critical thinking skills. However, investigable questions are fundamental for teachers to facilitate students to conduct open inquiry learning at the beginning of the process. In the study, the teacher-researcher introduced the Investigable Question Formulation Technique as an intervention to facilitate pupils to generate investigable questions. The study's methods of (i) planning action, (ii) taking action, (iii) collecting and analysing data, and (iv) reflecting on actions in two cycles successfully assisted the teacher-researcher in improving classroom practice. In traditional teaching practices, the teacher-researcher realised that pupils think that the experiment or activity written in the textbook is fixed and that procedures are already written in a structured format. The teacher-researcher did not believe that was part of the process of inquiry. Thus, in this study, the teacher-researcher inquired how she could stimulate pupils' inquiry. Should she change the curriculum? Or did she need to change the way she encouraged pupils to think through question focus? These questions led the teacher-researcher to make decisions to improve questioning strategies, and thus to facilitate pupils to generate investigable questions.

In the taking action phase, each record of questions generated by the pupils was kept in a notebook. The teacher-researcher analysed the questions generated by pupils based on Chin's (2002) framework of the Typology of Investigable and Noninvestigable Questions. The study found that the question focus provided to pupils to some extent influenced their ability to generate investigable questions. This was evident when in Cycle 1, the teacher-researcher used the menstrual cycle diagram as the question focus; however, the pupils only developed two investigable questions. Thus, the teacher-researcher conducted Cycle 
2 with the same objective but using a concrete material as the question focus. As a result of changing the question focus, the pupils successfully generated five investigable questions in Cycle 2. A total of five kinds of investigable questions were successfully generated by the pupils in this study, namely exploratory, validation of mental models, comparison, predictive and descriptive. In conclusion, to develop investigable questions, pupils need to continuously and consistently practise, and teachers need to provide the appropriate tools to enable this process. Although the process takes time, generating investigable questions will positively impact pupils' thinking and ability to inquire.

Author contributions: All authors have sufficiently contributed to the study, and agreed with the results and conclusions.

Funding: No funding source is reported for this study.

Declaration of interest: No conflict of interest is declared by authors.

\section{REFERENCES}

Allan, F., Herbert, A., Peter, P., \& Bridget, S. (2018). Teachers investigate their work. https://doi.org/10.4324/9781315398822

Bell, R. L., Smetana, L., \& Binns, I. (2005). Simplifying inquiry instruction. The Science Teacher, 30-33.

Brown G., Leonard G., \& Arthur-Kelly, M. (2016). Writing SMARTER goals for professional learning and improving classroom practices. Reflective Practice, 17(5), 621-635. https://doi.org/10.1080/14623943.2016.1187120

Chin, C. (2002). Open investigations in science: Posing problems and asking investigative questions. Teaching and Learning, 23(2), 155-166. https://doi.org/10.1080/0263514022000030499

Chin, C., \& Kayalvizhi, G. (2002). Posing problems for open investigations: What questions do pupils ask? Research in Science \& Technological Education, 20(2), 269-287. https://doi.org/10.1080/0263514022000030499

Chin, C., \& Osborne, C. (2008). Pupils' questions: A potential resource for teaching and learning science. Studies in Science Education, 44(1), 1-39. https://doi.org/10.1080/03057260701828101

Chin, C., \& Osborne, J. (2010). Supporting argumentation through pupils' questions: Case studies in science classrooms. Journal of the Learning Sciences, 19(2), 230-284. https://doi.org/10.1080/10508400903530036

Dillon, J. T. (1988). The remedial status of student questioning. Journal of Curriculum Studies, 20(3), $197-210$. https://doi.org/10.1080/0022027880200301

Fitzgerald, M., Danaia, L., \& McKinnon, D. H. (2019). Barriers inhibiting inquiry-based science teaching and potential solutions: Perceptions of positively inclined early adopters. Research in Science Education, 49(2), 543-566. https://doi.org/10.1007/s11165-017-9623-5

Harrak, F., Bouchet, F., \& Luengo, V. (2019). From pupils' questions to pupils' profiles in a blended learning environment. Journal of Learning Analytics, 6(1), 54-84. https://doi.org/10.18608/jla.2019.61.4

Herr, K., \& Anderson, G. L. (2005). The action research dissertation: A guide for pupils and faculty. SAGE Publications, Inc. https://doi.org/10.4135/9781452226644

Jacques, L. A., Cian, H., Herro, D. C., \& Quigley, C. (2020). The impact of questioning techniques on STEAM instruction. Action in Teacher Education, 42(3), 290-308. https://doi.org/10.1080/01626620.2019.1638848

Kemmis, S., McTaggart, R., \& Nixon, R., (2014). The action research planner: Doing critical participatory action research. Springer.

Keys, C. W. (1998). A study of grade six pupils generating questions and plans for open-ended science investigations. Research in Science Education, 28(3), 301-316. https://doi.org/10.1007/BF02461565

Laronde, G., \& MacLeod, K. (2012). Modeling various teaching methods in a faculty of education in science education: Chalk and talk, virtual labs or hovercrafts. Journal of College Teaching \& Learning (TLC), 9(2), $107-114$. https://doi.org/10.19030/tlc.v9i2.6905

Li, W. S. S., \& Arshad, M. Y. (2015). Inquiry practices in Malaysian secondary classroom and model of inquiry teaching based on verbal interaction. Malaysian Journal of Learning and Instruction, 12, 151-175. https://doi.org/10.32890/mjli2015.12.8

Lock, R. (1990). Open-ended, problem-solving investigations. School Science Review, 71(256), 63-72.

McNiff, J. (2007). My story is my living educational theory. In D. J. Clandinin (Ed.), Handbook of narrative inquiry: Mapping a methodology (pp. 308-329). Sage Publications Ltd. https://doi.org/10.4135/9781452226552.n12

McNiff, J. (2017). Action research: All you need to know. Sage Publications Ltd.

Ministry of Education [MOE]. (2013). Malaysia Education Blueprint 2013-2025. Ministry of Education Malaysia.

Newell, A., \& Simon, H. A. (1972). Human problem-solving. Prentice Hall.

Nik Yusuf, N. A., Abdullah, N., \& Mohamed Noh, N. (2017). Scientific identity and inquiry-based teaching amongst secondary school adolescents. Malaysian Science and Mathematics Education Journal, 7(2), 72-84. https://doi.org/10.37134/jpsmm.vol7.2.6.2017

Othman, I., \& Md Salleh, N. (2019). Pendekatan konstruktivisme dalam pengembangan kurikulum: Kesannya ke atas penguasaan kemahiran proses sains [Constructivist approaches in curriculum development: Its impact on mastery of science process skills]. Malaysian Science and Mathematics Education Journal, 3(1), 60-71.

Rezba, R. J., Auldridge, T., \& Rhea, L. (1999). Teaching \& learning the basic science skills.

Riel, M. (2010). The center for collaborative action research @ Pepperdine University. Inquiry in Education, 1(1), 1-3. 
Rothstein, D., \& Santana, L. (2017). Make just one change: Teach pupils to ask their own questions. Harvard Education Press.

Sabu, N., Mohamed Noh, N., Che Ahmad, C. N., \& Abdullah, N. (2018). Kesan ejen pedagogi dan rangsangan multimedia dalam koswer nutri-score terhadap kemahiran berfikir aras tinggi [Effects of pedagogical agents and multimedia stimuli in nutri-score courseware on high-level thinking skills]. Malaysian Science and Mathematics Education Journal, 8(2), 60-73. https://doi.org/10.37134/jpsmm.vol8.2.6.2018

Salavera, C., Usán, P., \& Teruel, P. (2019). Contextual problems, emotional intelligence and social skills in Secondary Education pupils. Gender differences. Annales Médico-Psychologiques, 177, 223-230. https://doi.org/10.1016/j.amp.2018.07.008

Scardamalia, M., \& Bereiter, C. (1992). Text-based and knowledge-based questioning by children. Cognition and Instruction, 9(3), 177-199. https://doi.org/10.1207/s1532690xci0903_1

Scriven, M., \& Paul, R. (2008). Defining critical thinking. Foundation for Critical Thinking. http://www.criticalthinking.org/aboutCT/define_critical_thinking.cfm

Shodell, M. (1995). The classroom student questions as course in biology curriculum is continuous. The American Biology Teacher, 57(5), 278-281. https://doi.org/10.2307/4449992

Venema, S., \& Lodge, J. M. (2013). Capturing dynamic presentation: Using technology to enhance the chalk and the talk. Australasian Journal of Educational Technology, 29(1), 20-31. https://doi.org/10.14742/ajet.62

Watts, M. (1991). The science of problem-solving. Cassell Educational Ltd.

Whitehead, J. (1989). Creating a living educational theory from questions of the kind, 'How do I improve my practice?'. Cambridge Journal of Education, 19(1), 41-52. https://doi.org/10.1080/0305764890190106

Yin Peen, T., \& Yusof Arshad, M. (2014). Teacher and student questions: A case study in Malaysian secondary school problem-based learning. Asian Social Science, 10(4), 174-182. https://doi.org/10.5539/ass.v10n4p174

Yoon, H. G., Joung, Y. J., \& Kim, M. (2012). The challenges of science inquiry teaching for pre-service teachers in elementary classrooms: Difficulties on and under the scene. Research in Science Education, 42(3), 589-608. https://doi.org/10.1007/s11165011-9212-y

Zion, M., \& Mendelovici, R. (2012). Moving from structured to open inquiry: Challenges and limits. Science Education International, 23(4), 383-399. 